\title{
GUÍA METODOLÓGICA COLEGIO EL CARMELO
}

\section{Resumen.}

\author{
Paulo Germán García Murillo \\ Juana Yadira Martín Perico \\ Julio Ernesto Rojas Mesa \\ Bernardo Garibello Suan \\ Laura Belkis Parada Romero
}

En el contexto de la pandemia por COVID-19 se plantea nuevos retos en los procesos de aprendizaje de la ciencias naturales, ya que se restringe completamente la presencialidad en colegios de básica primaria, lo que dificulta el desarrollo de experiencias de tipo experimental; en respuesta a lo anterior se genera el presente proyecto, que tiene como propósito principal la generación de competencias STEAM (ambientales, tecnológicas y pedagógicas y artísticas), para cursos de quinto grado de básica primaria en un colegio de la localidad de Teusaquillo (EI Carmelo) en la ciudad de Bogotá D.C. mediante una experiencia agrícola urbana. Para el desarrollo de lo anterior se diseñaron dos prácticas experimentales para desarrollo en casa, utilizando en ambos casos semillas de fríjol (variedad cargamanto), el cual es de fácil adquisición en los momentos de abastecimiento de alimentos

El en primer ensayo se evalúa el efecto de la pregerminación controlada de semillas en matriz sólida, para lo cual se utilizará cascarilla de arroz o residuos de café (cuncho) evaluando el porcentaje y tiempo de germinación con y sin pregerminación; el segundo ensayo se evaluará el crecimiento y desarrollo de plántulas de fríjol en tres intensidades de luz diferentes (plena, media y en oscuridad).

Se espera como resultado del proyecto, generar una guía pedagógica para profesores, padres de familia y estudiantes que permita el desarrollo de competencias STEAM y ambientales, que pueda incorporarse como práctica en cursos de ciencias naturales y en los hogares de los estudiantes, como elemento de entendimiento de la transformación de la materia orgánica, seguridad y soberanía alimentaria, tecnologías limpias, agricultura urbana y nutrición.

Palabras Claves: ciencias naturales, seguridad alimentaria, pregerminación, fríjol

\section{Introducción.}

Las actuales investigaciones en el campo de la didáctica de las ciencias señalan dos tendencias significativas: i). la necesidad de la alfabetización de la ciencia a fin de encaminar el aprendizaje a la realidad actual y ii). la tendencia mundial de los jóvenes a elegir disciplinas diferentes a las de corte científico y tecnológico (Nugent \& Rhinard, 2015); Gisbert, M., \& Esteve, 2016; GarcíaPeñalvo, 2016; Perales \& Aguilera, 2019).

En este sentido, una de las alternativas más viables para el aprendizaje de las ciencias, desde la formación básica, la constituye el modelo STEM (Science, Technology, Engineering \& Mathematics), cuya finalidad fue agrupar estas 4 grandes áreas del conocimiento, con el propósito de desarrollar una nueva manera de enseñar, donde se combinen las ciencias, matemáticas y la tecnología, a fin de dar solución a problemas del contexto. Dicho modelo, en 2006 fue redefinido por Georgette Yakman como STEAM (STEM+Arts) concebido como un enfoque transdisciplinar encaminado a la resolución de problemas reales (Aguirre, Vaca, M. \& Vaca, C., 2019; Perales \& Aguilera, 2019). 
De acuerdo con lo anterior, en el siguiente cuadro se puntualizan los orígenes, las estrategias de desarrollo y la finalidad del modelo, que se propone desde la academia como una alternativa a las demandas de la sociedad relacionadas directa e indirectamente con los avances científicos y tecnológicos.

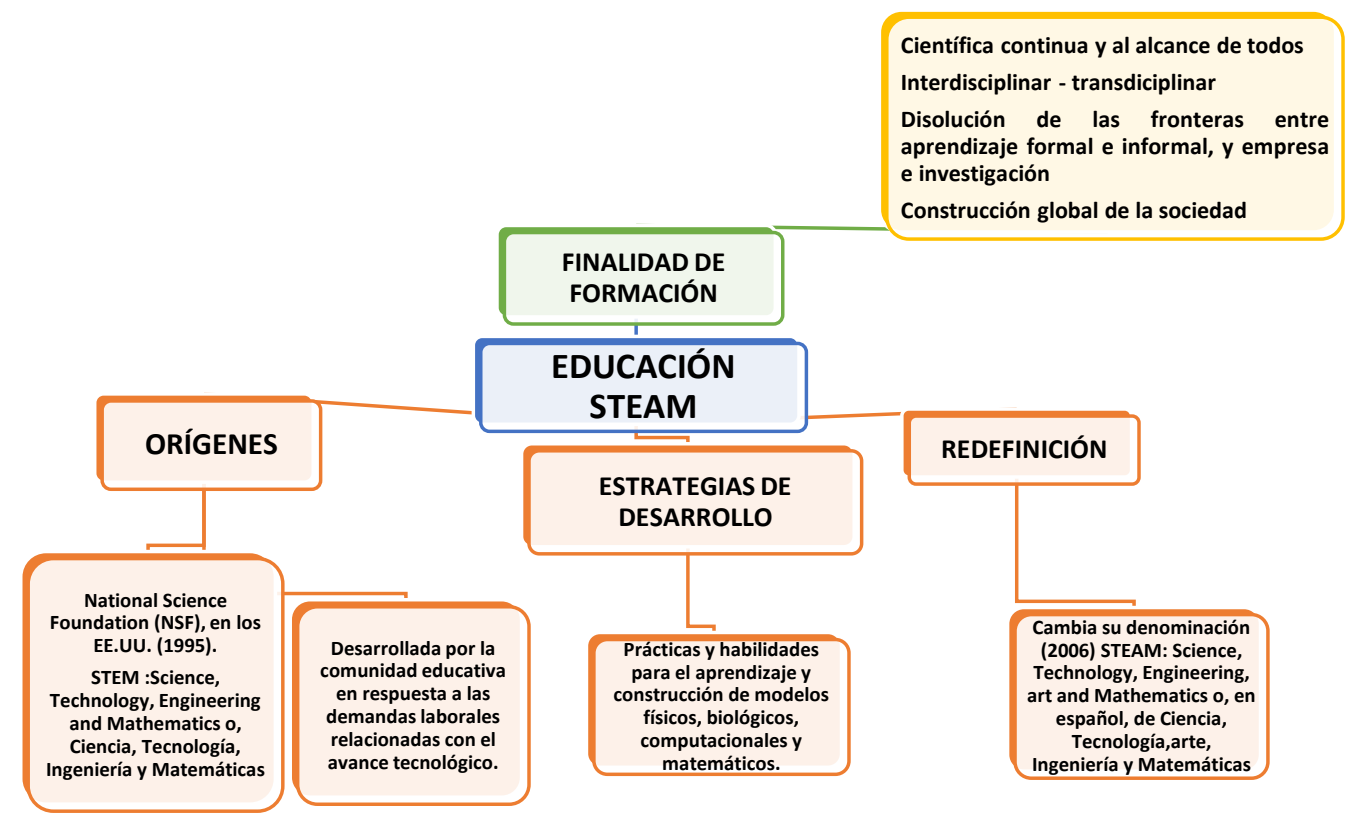

Mapa 1. Modelo STEAM. Desarrollo y finalidad pedagógica. Fuente propia.

Asimismo, por medio de la educación STEAM, la indagación puede ser entendida desde dos perspectivas. La primera perspectiva envuelve a todo proceso que requiere del trabajo profesional científico, en donde requiere del proceso de investigación realizado por una persona con el fin de darle solución a una problemática y, la segunda perspectiva, está basada en la dinámica de aprendizaje, es decir desde un enfoque pedagógico, en donde los estudiantes desarrollan habilidades científicas que le permiten construir ideas que sigan la dinámica científica para la resolución de problemáticas y que a su vez, les ayude construir un pensamiento crítico e investigativo en este campo (Rodríguez, 2016).

Es evidente, que el proceso de aprendizaje no solo depende de la labor realizada por el profesor y el estudiante, también se hace necesaria la participación de la familia, quien cumple un papel importante en el refuerzo de los aprendizajes, la satisfacción de dudas, el acompañamiento en los descubrimientos y las inferencias, puesto que el aprendizaje basado en proyectos, permite el aprendizaje descubriendo, indagando y observando (Trujillo, 2015; Barrera, 2017). 


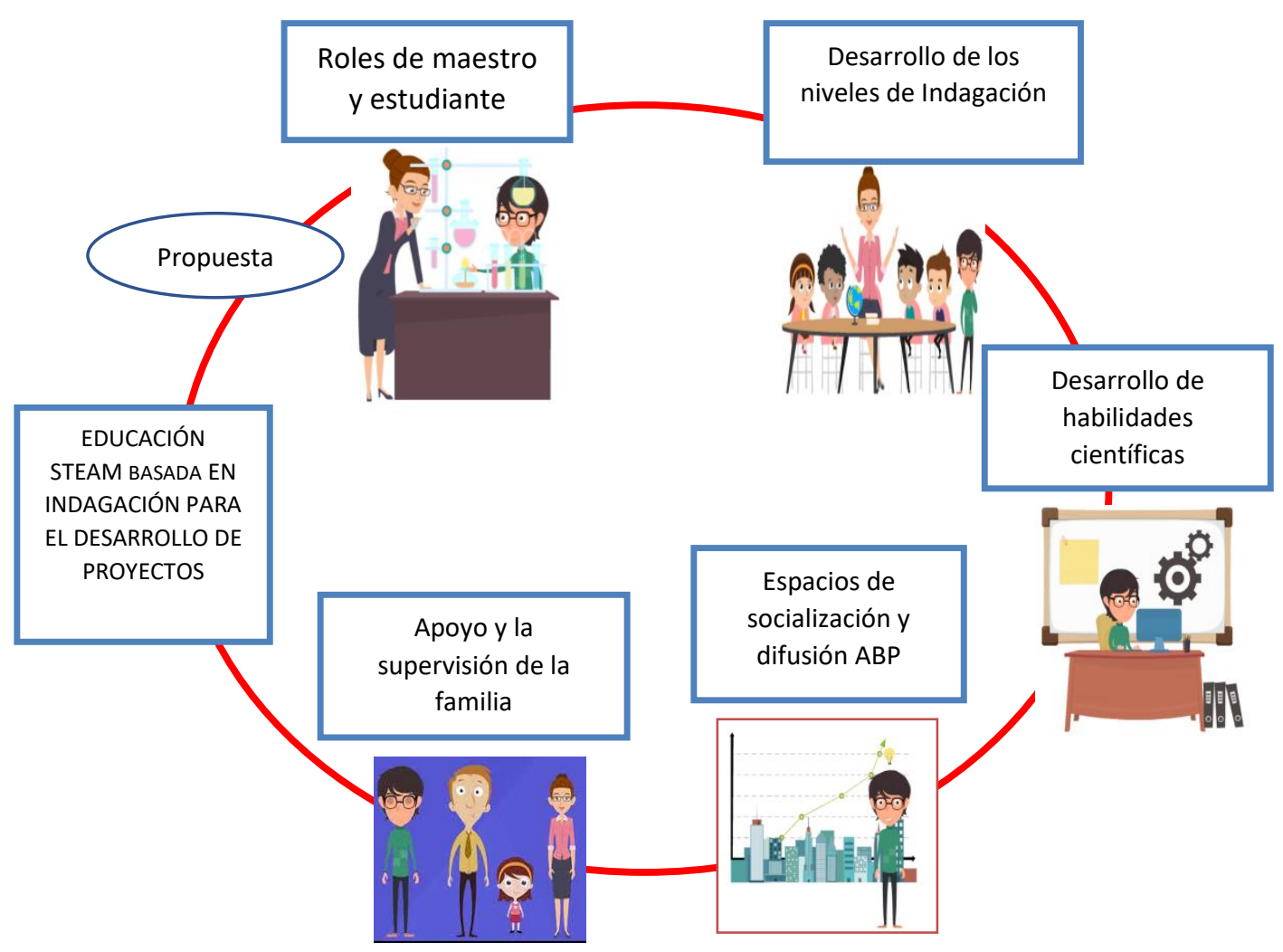

Esquema 1. Estructura de desarrollo modelo STEAM, basado en la indagación para el aprendizaje basado en proyectos. Fuente propia.

\section{Justificación.}

La presente propuesta es pertinente desde el punto de vista pedagógico y social en el contexto del Colegio el Carmelo dado que permite entre otros:

- Fortalecer los procesos investigativos en profesores y estudiantes.

- Fomentar las competencias científicas en los estudiantes a través del desarrollo de un proyecto transversal, que propicia diferentes momentos de aprendizaje y que involucra a toda la comunidad académica (docentes, estudiantes, padres de familia).

- La experiencia agrícola urbana permite que el estudiante maneje conceptos de biología, química, ciencias sociales, matemáticas, arte y tecnología, puesto que a medida que va comprendiendo el proceso de cultivo y crecimiento de la hortaliza, también va aprendiendo conceptos de otras áreas y los va involucrando a su aprendizaje, de forma natural y autónoma.

- Brindar una experiencia académica que permita a los estudiantes justificar la investigación en la producción agrícola en su contexto, mediante la revisión de bibliografía y el análisis de las problemáticas generadas por los residuos sólidos vegetales y otras relacionadas con la nutrición.

- De otra parte, permite que los estudiantes generen elementos de discusión acerca de la factibilidad de la investigación; en términos de la planeación y anticipación de los requerimientos 
y ejecución de un proyecto productivo, mediante el diseño experimental, elección de técnicas de recolección de información, muestreo y análisis de resultados.

- El desarrollo del laboratorio virtual permite al estudiante estar en contacto con las nuevas herramientas tecnológicas y emplearlas para su aprendizaje, a través de un entorno digital creado con el que puede analizar una experiencia agrícola urbana.

\section{Objetivo del proyecto.}

Implementar las competencias STEAM (ambientales, tecnológicas y pedagógicas), en el curso de quinto de primaria del Colegio el Carmelo de la ciudad de Bogotá D.C. a través de una experiencia agrícola urbana.

\section{Cronograma de trabajo.}

A continuación, se establecen los tiempos de ejecución del proyecto, los participantes y los resultados esperados.

\begin{tabular}{|c|c|c|c|}
\hline TIEMPO & ACTIVIDAD & PARCTICIPANTES & RESULTADO \\
\hline $\begin{array}{l}4 \quad \text { semanas } \\
\text { (agosto) }\end{array}$ & $\begin{array}{l}\text { Piloto con el equipo docente } \\
\text { - } \text { Registro de medidas y } \\
\text { registro fotográfico } \\
\text { - Sistematización de } \\
\text { resultados }\end{array}$ & 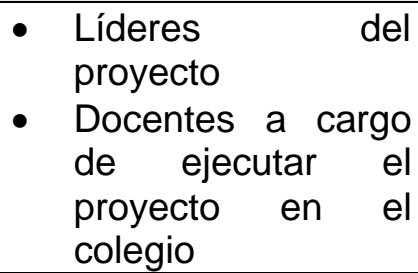 & $\begin{array}{l}\text { Desarrollo de la guía } \\
\text { metodológica }\end{array}$ \\
\hline $\begin{array}{l}8 \text { semanas } \\
\text { (septiembre- } \\
\text { octubre) }\end{array}$ & $\begin{array}{l}\text { Implementación de la guía } \\
\text { - } \text { Registro de medidas y } \\
\text { registro fotográfico } \\
\text { - Sistematización de } \\
\text { resultados }\end{array}$ & $\begin{array}{l}\text { - } \text { Profesores } \\
\text { - Estudiantes } \\
\text { - Padres de familia } \\
\text { - } \text { Apoyo Líderes del } \\
\text { proyecto }\end{array}$ & $\begin{array}{l}\text { Fase de cultivo y cosecha } \\
\text { Identificación de } \\
\text { Competencias STEAM y } \\
\text { de sostenibilidad }\end{array}$ \\
\hline $\begin{array}{l}12 \text { semanas } \\
\text { (agosto- } \\
\text { Octubre) }\end{array}$ & $\begin{array}{l}\text { Exploración del simulador virtual } \\
\text { - Registro de datos en el } \\
\text { formato Excel }\end{array}$ & $\begin{array}{l}\text { - } \text { Profesores } \\
\text { - Estudiantes } \\
\text { - } \text { Apoyo Líderes del } \\
\text { proyecto }\end{array}$ & $\begin{array}{lr}\text { Visualización } & \text { de } \\
\text { crecimiento y cultivo } \\
\text { Cuantificación de } \\
\text { parámetros de crecimiento } \\
\text { de las plantas } \\
\begin{array}{l}\text { Modelo predictivo de } \\
\text { crecimiento del cultivo }\end{array}\end{array}$ \\
\hline $\begin{array}{l}1 \text { semana } \\
\text { (última } \\
\text { semana de } \\
\text { octubre) }\end{array}$ & $\begin{array}{l}\text { Festival gastronómico } \\
\text { - Grabación de la } \\
\text { preparación de alimentos }\end{array}$ & $\begin{array}{ll}\text { - } & \text { Profesores } \\
\text { - } & \text { Estudiantes } \\
\text { - } & \text { Apoyo Líderes del } \\
& \text { proyecto } \\
\text { - } & \text { Padres de familia } \\
\text { - } & \text { Apoyo Líderes del } \\
& \text { proyecto }\end{array}$ & $\begin{array}{l}\text { Informe de los contenidos } \\
\text { nutricionales identificados } \\
\text { en la comida preparada }\end{array}$ \\
\hline
\end{tabular}




\section{Guía del proceso de experiencia agrícola.}

A continuación, se expone la guía del desarrollo de la experiencia agrícola urbana, exaltando los tiempos de ejecución, la actividad a realizar, el núcleo temático a tratar en el contexto de las competencias para quinto grado y las preguntas integradoras que permiten aplicar el modelo STEAM.

\begin{tabular}{|c|c|c|c|}
\hline \multicolumn{4}{|c|}{$\begin{array}{l}\text { EVALUACIÓN DE LA PRE-GERMINACIÓN CONTROLADA DE SEMILLAS DE FRÍJOL } \\
\text { (Experimento 1) }\end{array}$} \\
\hline \multicolumn{4}{|c|}{ Obtención del material Vegetal } \\
\hline TIEMPO & ACTIVIDAD & NÚCLEO TEMÁTICO & COMPETENCIA \\
\hline $\begin{array}{l}\text { SEMANA } \\
1\end{array}$ & & $\begin{array}{l}\text { - Consulta aspectos } \\
\text { teóricos del fríjol y taller } \\
\text { de análisis }\end{array}$ & $\begin{array}{l}\text { Emplea diferentes } \\
\text { medios de consulta } \\
\text { para conocer los } \\
\text { conceptos de } \\
\text { semilla, } \\
\text { germinación, } \\
\text { leguminosas, } \\
\text { bacterias fijadoras } \\
\text { de nitrógeno, } \\
\text { importancia } \\
\text { nutricional del fríjol, } \\
\text { agricultura urbana, } \\
\text { etc. }\end{array}$ \\
\hline \multicolumn{4}{|c|}{$\begin{array}{l}\text { - ¿Qué fenómenos biológicos ocurren en el proceso de germinación? } \\
\text { - ¿Qué asociaciones simbióticas establece el fríjol con las bacterias del suelo? } \\
\text { - ¿Qué platos representativos se preparan con el frijol en Colombia y en el mundo? }\end{array}$} \\
\hline \multirow{2}{*}{\multicolumn{4}{|c|}{$\begin{array}{l}\text { Procedimiento (semana 1): Aprovecha la visita de uno de tus padres para aprovisionamiento de víveres en contexto } \\
\text { de cuarentena y solicítale la compra de semillas de frijol (una libra); para la realización del experimento } 1 \text { y } 2 \text {. }\end{array}$}} \\
\hline \multicolumn{2}{|c|}{ Montaje experimento pre-germinación } & & \\
\hline TIEMPO & ACTIVIDAD & NÚCLEO TEMÁTICO & COMPETENCIA \\
\hline \multirow[t]{2}{*}{$\begin{array}{l}\text { SEMANA } 2 \\
\text {-DÍA } 1\end{array}$} & & $\begin{array}{l}\text { - Selección de elementos } \\
\text { de laboratorio y análisis } \\
\text { de su uso }\end{array}$ & $\begin{array}{l}\text { Identifica } \\
\text { elementos de uso } \\
\text { para el laboratorio }\end{array}$ \\
\hline & Figura 2. Preparación del desinfectante. & $\begin{array}{l}\text { - } \quad \text { Procesos asociados a } \\
\text { la germinación. } \\
\text { - } \quad \text { Prevención de } \\
\text { fitopatógenos. } \\
\text { - Manejo de materiales } \\
\text { químicos. }\end{array}$ & $\begin{array}{ll}\text { - } & \text { Explora sobre la } \\
\text { acción del } \\
\text { hipoclorito de sodio } \\
\text { en la desinfección } \\
\text { de alimentos } \\
\text { - Analiza la } \\
\text { importancia de la } \\
\text { desinfección de } \\
\text { alimentos para la } \\
\text { prevención de los } \\
\text { fitopatógenos. } \\
\end{array}$ \\
\hline
\end{tabular}


Implementación de las competencias STEAM (ambientales, tecnológicas y pedagógicas), para cursos de básica primaria en colegios de la ciudad de Bogotá D.C. mediante una experiencia agrícola urbana.

\section{Universidad Santo Tomás}

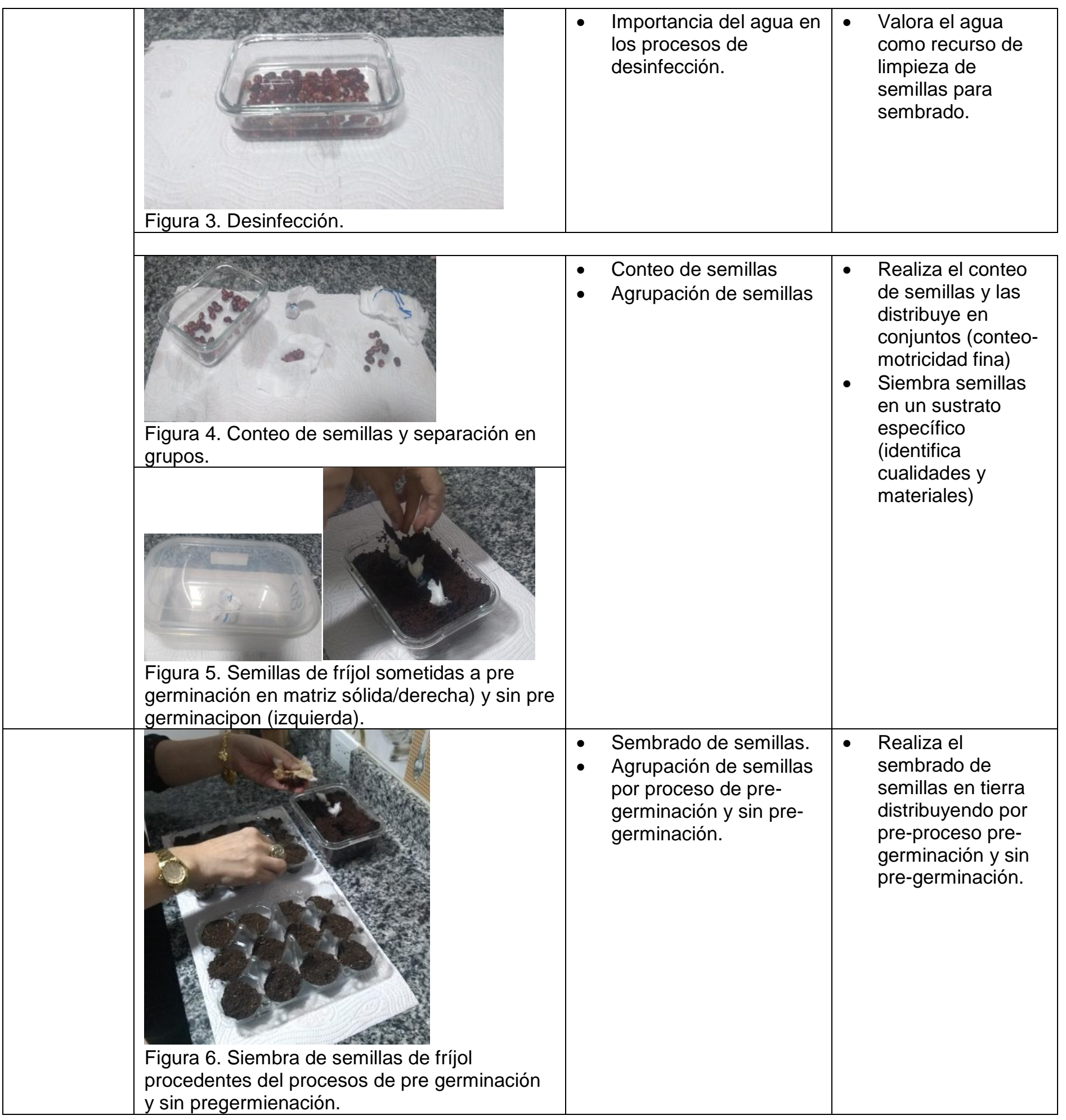


Implementación de las competencias STEAM (ambientales, tecnológicas y pedagógicas), para cursos de básica primaria en colegios de la ciudad de Bogotá D.C. mediante una experiencia agrícola urbana.

\section{Universidad Santo Tomás}

\section{Preparación del material vegetal}

\section{Procedimiento semana 2}

Para evitar el crecimiento de hongos y bacterias indeseables en las semillas de frijol, lave las semillas con abundante agua (Figura 1) y desinféctelas en una suspensión de hipoclorito de sodio (Clorox®) al $2 \%$ por 5 minutos (figura 3 ).

Esta suspensión se preparará agregando $200 \mathrm{ml}$ de Clorox® adicionándosele $300 \mathrm{ml}$ de agua; posteriormente, las semillas serán lavadas con abundante agua (hervida preferiblemente) durante 3 min por tres veces consecutivas (figura 2).

- ¿Por qué el uso de desinfectantes contribuye a la prevención de enfermedades en humanos, animales y plantas?

- ¿Cómo funciona el hipoclorito de sodio (Clorox®) como desinfectante?

- ¿Qué características tienen las bacterias y los hongos? ¿Qué similitudes y diferencias tienen entre ellos?

- Describa las diferentes etapas de la germinación.

- Describa las principales características de las leguminosas.

\section{Preparación de sustrato para la pre-germinación}

A partir del residuo de café (Cuncho) obtenido diariamente, se sugiere secarlo mediante su exposición al sol o en un horno a 80 a $100^{\circ} \mathrm{C}$ por 1 hora o sométalo 5 minutos en potencia alta en el horno microondas, lo anterior se realiza para evitar el crecimiento de microrganismos no deseados que puedan interferir con la germinación de las semillas en los diferentes ensayos o si lo prefiere puede utilizar cascarilla de arroz.

\section{Pre-germinación controlada de semillas}

Para la pre-germinación controlada de semillas de frijol, se utilizará un recipiente plástico con tapa. En éste se colocarán $200 \mathrm{~g}$ de residuos de café o (cuncho) cascarilla de arroz humedecida con $250 \mathrm{ml}$ de agua, que equivalía al $80 \%$ de la capacidad de retención del sustrato.

Posteriormente, las semillas de frijol serán divididas en 6 lotes, cada uno con 30 semillas (que puede ser colocadas en una toalla de papel (tabla 1). Tres de frijol que se someterán a pre-germinación y tres también de frijol, pero sin pre-germinación.

Tabla 1. Lotes de semillas de fríjol.

\begin{tabular}{|c|c|}
\hline $\begin{array}{c}\text { Con Pregerminación } \\
\text { (Bloque 1) }\end{array}$ & $\begin{array}{c}\text { Sin Pregerminación } \\
\text { (Bloque 2) }\end{array}$ \\
\hline 30 semillas & 30 semillas \\
\hline 30 semillas & 30 semillas \\
\hline 30 semillas & 30 semillas \\
\hline
\end{tabular}

Las semillas de fríjol sin pre-germinar, se dejarán entre un recipiente plástico vacío (sin sustrato) durante 48 horas y las correspondiente a la pregerminación, serán colocadas a $5 \mathrm{~cm}$ de profundidad en la matriz de residuos de café (cuncho) o cascarilla de arroz humedecida (figura 5).

Las cajas plásticas serán colocadas en un lugar fresco y seco durante 48 horas. Después de transcurrido este tiempo, todos los grupos de semillas de fríjol (30 unidades) que estaban en las cajas plásticas se sacarán y se sembrarán en los semilleros (cartones de huevos) (figura 6) con suelo de jardín en los mismos grupos dispuestos en la tabla 1. Estos semilleros se dejarán por ocho días en condiciones controladas de humedad (80\%), temperatura $\left(20{ }^{\circ} \mathrm{C}\right)$ y a luz ambiente.

Día 3. Se evaluará el porcentaje de germinación, cada día (24 horas) en cada grupo de semillas de cada bloque (

Tabla 2. Evaluación lotes de semillas de fríjol

\begin{tabular}{|c|c|c|c|c|c|c|c|c|}
\hline \multirow{2}{*}{ Tiempo } & \multicolumn{3}{|c|}{$\begin{array}{c}\text { Con pregerminar (Bloque 1) } \\
\% \text { de germinación }\end{array}$} & \multirow{2}{*}{ Promedio } & \multicolumn{3}{|c|}{$\begin{array}{c}\text { Sin Pregerminadas (Bloque 2) } \\
\% \text { de germinación }\end{array}$} & \multirow{2}{*}{ Promedio } \\
\hline & $\begin{array}{c}30 \\
\text { semillas }\end{array}$ & 30 semillas & $\begin{array}{c}30 \\
\text { semillas }\end{array}$ & & 30 semillas & $\begin{array}{c}30 \\
\text { semillas }\end{array}$ & $\begin{array}{c}30 \\
\text { semillas }\end{array}$ & \\
\hline \multicolumn{9}{|l|}{ Día 4} \\
\hline \multirow{2}{*}{\multicolumn{9}{|c|}{$\frac{\text { Día } 5}{\text { Día } 6}$}} \\
\hline & & & & & & & & \\
\hline Día 7 & & & & & & & & \\
\hline
\end{tabular}


Implementación de las competencias STEAM (ambientales, tecnológicas y pedagógicas), para cursos de básica primaria en colegios de la ciudad de Bogotá D.C. mediante una experiencia agrícola urbana.

\section{Universidad Santo Tomás}

Se considera una semilla germinada en el momento que emerge el tallo (figura 7).

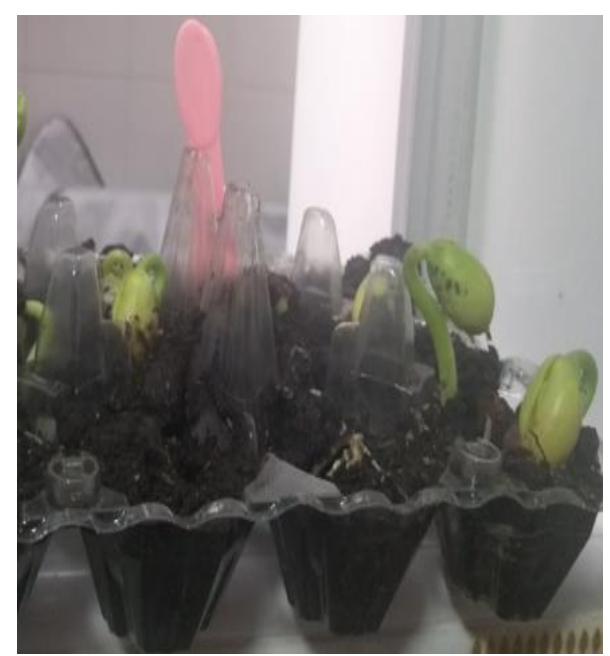

Figura 7. Semillas de fríjol germinadas.

¿Qué grupo de semillas germinaron más rápidamente?

¿Existe alguna diferencia en los porcentajes de germinación entre los bloques con pre-germinación y sin pregerminación?

Conclusiones del experimento:

\section{Experimento 2: Efecto de tres intensidades de luz sobre plántulas de fríjol}

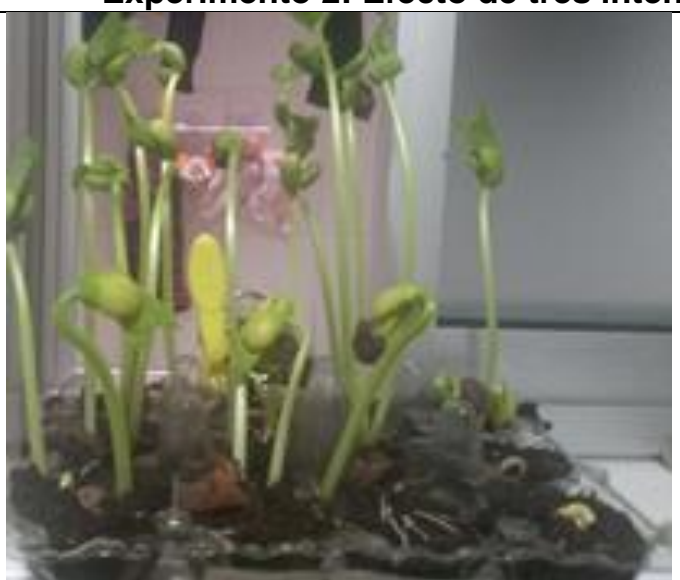

Figura 8. Selección de plantulas de frijol para realización de ensayo 2.
- Crecimiento y desarrollo de plántulas de fríjol.

- Fotosíntesis.

- Pigmentos involucrados en la fotosíntesis

- Crecimiento de plántulas de fríjol en tres intensidades de luz.
- Identifica las diferentes etapas de crecimiento de las plántulas de frijol.

- Realiza comparaciones de crecimiento de las plántulas en tres intensidades de luz diferentes midiendo longitud de tallos, número de hojas verdes, amarillas y vainas verdes.

- $\quad$ Mide longitudes (tallos y hojas).

- Realiza curvas de crecimiento. 
Implementación de las competencias STEAM (ambientales, tecnológicas y pedagógicas), para cursos de básica primaria en colegios de la ciudad de Bogotá D.C. mediante una experiencia agrícola urbana.

\section{Universidad Santo Tomás}

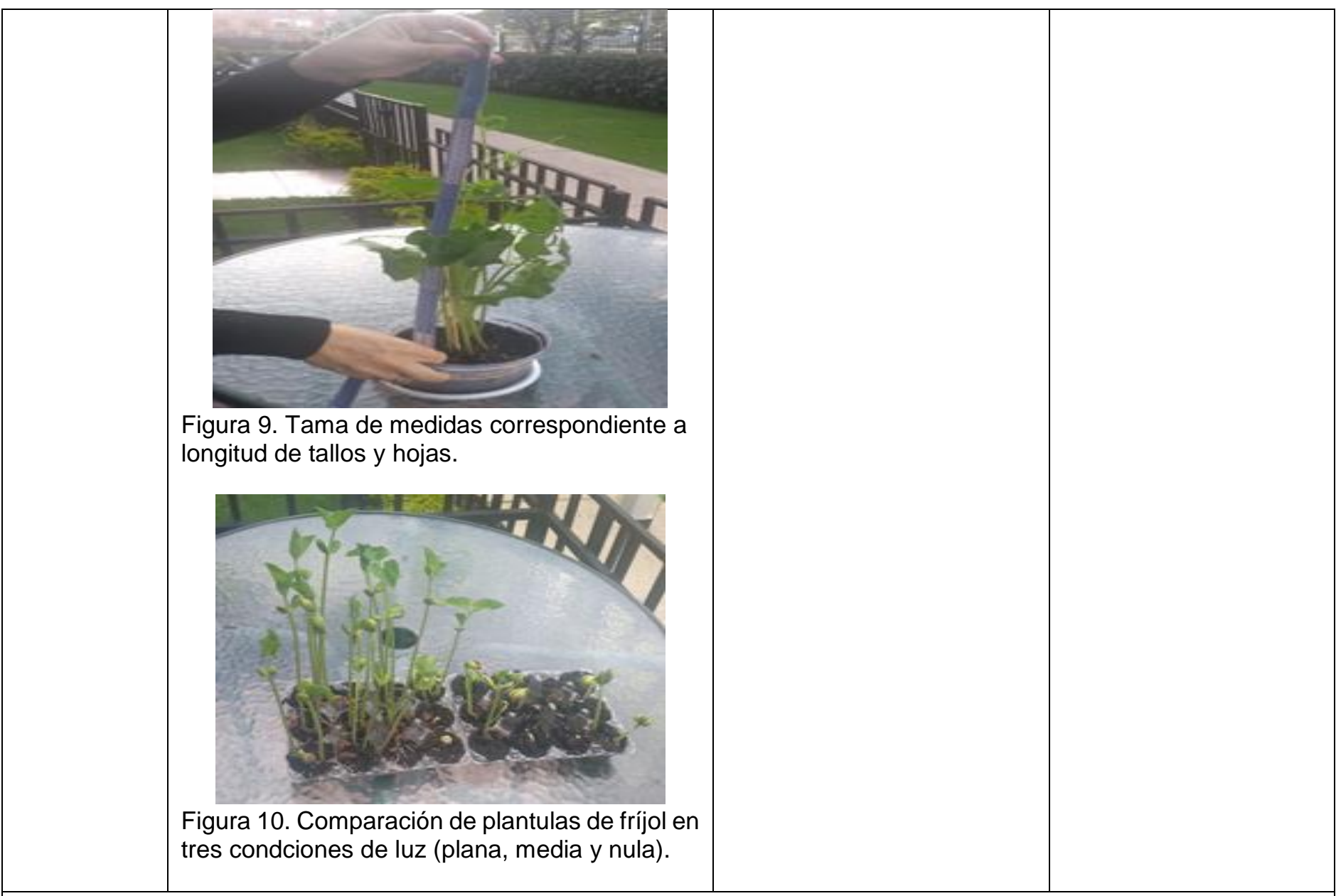

\section{Procedimiento semanas 3 y 4.}

A partir de las plántulas de fríjol obtenidos en el experimento 1, seleccione plántulas de frijol del mismo tamaño y que en promedio tengan de 2 a 4 hojas. Siembre tres plántulas a una distancia aproximada de $3 \mathrm{~cm}$ de forma equidistante (figura 8).

Un matero se colocará en presencia de luz solar plena, un segundo matero se colocará en presencia de un velo o poli sombra de ser posible y el tercero en total oscuridad.

Se evaluará el crecimiento y desarrollo de las plántulas cada 48 horas en todas las plántulas de todos los tratamientos en cada bloque (plántulas de frijol o de fresa), hasta cuando por las plántulas de alguno de los tratamientos alcance la producción de frutos maduros (vainas de fríjol o frutos de fresa). Mantenga riego diario para cada matero de forma equitativa para cada tratamiento.

Tabla 3. Medición de longitud de tallos de fríjol en tres intensidades de luz.

\begin{tabular}{|c|c|c|c|c|c|c|c|c|c|c|c|c|}
\hline \multirow[b]{2}{*}{ Tiempo } & \multicolumn{4}{|c|}{ Luz plena } & \multicolumn{4}{|c|}{ Luz media } & \multicolumn{4}{|c|}{ Sin luz } \\
\hline & $\begin{array}{c}\text { Planta } \\
1\end{array}$ & $\begin{array}{c}\text { Planta } \\
2\end{array}$ & $\begin{array}{c}\text { Planta } \\
3\end{array}$ & Prom. & $\begin{array}{c}\text { Planta } \\
1\end{array}$ & $\begin{array}{c}\text { Planta } \\
2\end{array}$ & $\begin{array}{c}\text { Planta } \\
3\end{array}$ & Prom. & $\begin{array}{c}\text { Planta } \\
1\end{array}$ & $\begin{array}{c}\text { Planta } \\
2\end{array}$ & $\begin{array}{c}\text { Planta } \\
3\end{array}$ & Prom. \\
\hline Día 1 & & & & & & & & & & & & \\
\hline Día 3 & & & & & & & & & & & & \\
\hline Día 5 & & & & & & & & & & & & \\
\hline Día 7 & & & & & & & & & & & & \\
\hline Día 9 & & & & & & & & & & & & \\
\hline Día 11 & & & & & & & & & & & & \\
\hline Día 13 & & & & & & & & & & & & \\
\hline Día 15 & & & & & & & & & & & & \\
\hline
\end{tabular}

Tabla 4. Medición del grosor de los tallos de fríjol en tres intensidades de luz. Esta medida se toma en la parte media del tallo. 
Implementación de las competencias STEAM (ambientales, tecnológicas y pedagógicas), para cursos de básica primaria en colegios de la ciudad de Bogotá D.C. mediante una experiencia agrícola urbana.

Universidad Santo Tomás

\begin{tabular}{|c|c|c|c|c|c|c|c|c|c|c|c|c|}
\hline \multirow[b]{2}{*}{ Tiempo } & \multicolumn{4}{|c|}{ Luz plena } & \multicolumn{4}{|c|}{ Luz media } & \multicolumn{4}{|c|}{ Sin luz } \\
\hline & $\begin{array}{c}\text { Planta } \\
1\end{array}$ & $\begin{array}{c}\text { Planta } \\
2\end{array}$ & $\begin{array}{c}\text { Planta } \\
3\end{array}$ & Prom. & $\begin{array}{c}\text { Planta } \\
1\end{array}$ & $\begin{array}{c}\text { Planta } \\
2\end{array}$ & $\begin{array}{c}\text { Planta } \\
3\end{array}$ & Prom. & $\begin{array}{c}\text { Planta } \\
1\end{array}$ & $\begin{array}{c}\text { Planta } \\
2\end{array}$ & $\begin{array}{c}\text { Planta } \\
3\end{array}$ & Prom. \\
\hline Día 1 & & & & & & & & & & & & \\
\hline Día 3 & & & & & & & & & & & & \\
\hline Día 5 & & & & & & & & & & & & \\
\hline Día 7 & & & & & & & & & & & & \\
\hline Día 9 & & & & & & & & & & & & \\
\hline Día 11 & & & & & & & & & & & & \\
\hline Día 13 & & & & & & & & & & & & \\
\hline Día 15 & & & & & & & & & & & & \\
\hline
\end{tabular}

¿Cómo influye la luz el crecimiento de los tallos de las plantas de fríjol?

¿Es el crecimiento de los tallos de las plantas directamente proporcional o inversamente proporcional al paso del tiempo? ¿El grosor de los tallos de las plantas aumenta o disminuye con el paso del tiempo?

¿El grosor de los tallos varía al mismo ritmo que la longitud de los tallos? Es decir, ¿Un tallo el doble de largo tendrá el doble de ancho?

Grafique el crecimiento de los tallos en una hoja de papel milimetrado o en Excel. El eje de las x corresponde al tiempo (día) y en el eje de la y longitud de tallos (cm).

Conclusiones.

Tabla 5. Medición de numero de hojas verdes de fríjol en tres intensidades de luz.

\begin{tabular}{|c|c|c|c|c|c|c|c|c|c|c|c|c|}
\hline \multirow[b]{2}{*}{ Tiempo } & \multicolumn{4}{|c|}{ Luz plana } & \multicolumn{4}{|c|}{ Luz media } & \multicolumn{4}{|c|}{ Sin luz } \\
\hline & $\begin{array}{c}\text { Planta } \\
1\end{array}$ & $\begin{array}{c}\text { Planta } \\
2\end{array}$ & $\begin{array}{c}\text { Planta } \\
3\end{array}$ & Prom. & $\begin{array}{c}\text { Planta } \\
1\end{array}$ & $\begin{array}{c}\text { Planta } \\
2\end{array}$ & $\begin{array}{c}\text { Planta } \\
3\end{array}$ & Prom. & $\begin{array}{c}\text { Planta } \\
1\end{array}$ & $\begin{array}{c}\text { Planta } \\
2\end{array}$ & $\begin{array}{c}\text { Planta } \\
3\end{array}$ & Prom. \\
\hline Día 1 & & & & & & & & & & & & \\
\hline Día 3 & & & & & & & & & & & & \\
\hline Día 5 & & & & & & & & & & & & \\
\hline Día 7 & & & & & & & & & & & & \\
\hline Día 9 & & & & & & & & & & & & \\
\hline Día 11 & & & & & & & & & & & & \\
\hline Día 13 & & & & & & & & & & & & \\
\hline Día 15 & & & & & & & & & & & & \\
\hline
\end{tabular}

Tabla 6. Medición de numero de hojas amarillentas (cloróticas) de fríjol en tres intensidades de luz.

\begin{tabular}{|c|c|c|c|c|c|c|c|c|c|c|c|c|}
\hline \multirow[b]{2}{*}{ Tiempo } & \multicolumn{4}{|c|}{ Luz plana } & \multicolumn{4}{|c|}{ Luz media } & \multicolumn{4}{|c|}{ Sin luz } \\
\hline & $\begin{array}{c}\text { Planta } \\
1\end{array}$ & $\begin{array}{c}\text { Planta } \\
2\end{array}$ & $\begin{array}{c}\text { Planta } \\
3\end{array}$ & Prom. & $\begin{array}{c}\text { Planta } \\
1\end{array}$ & $\begin{array}{c}\text { Planta } \\
2\end{array}$ & $\begin{array}{c}\text { Planta } \\
3\end{array}$ & Prom. & $\begin{array}{c}\text { Planta } \\
1\end{array}$ & $\begin{array}{c}\text { Planta } \\
2\end{array}$ & $\begin{array}{c}\text { Planta } \\
3\end{array}$ & Prom. \\
\hline Día 1 & & & & & & & & & & & & \\
\hline Día 3 & & & & & & & & & & & & \\
\hline Día 5 & & & & & & & & & & & & \\
\hline Día 7 & & & & & & & & & & & & \\
\hline Día 9 & & & & & & & & & & & & \\
\hline Día 11 & & & & & & & & & & & & \\
\hline Día 13 & & & & & & & & & & & & \\
\hline Día 15 & & & & & & & & & & & & \\
\hline
\end{tabular}

¿Cómo influye la luz el número de hojas en plantas de fríjol?

Grafique el número de hojas en una hoja de papel milimetrado o en Excel. El eje de las x corresponde al tiempo (día) y en el eje de la y número de hojas.

¿El número de hojas de las plantas aumenta con el tiempo o disminuye?

¿De cada ramificación del tallo, nota que salen el mismo número de hojas? ¿Cuántas? ¿Cada cuánto tiempo?

¿Si el número de hojas que salen por ramificación son las mismas y de mantenerse esta tendencia, es posible predecir, cuántas habrá después de un mes, seis meses, doce meses?

Conclusiones. 
Implementación de las competencias STEAM (ambientales, tecnológicas y pedagógicas), para cursos de básica primaria en colegios de la ciudad de Bogotá D.C. mediante una experiencia agrícola urbana.

\section{Universidad Santo Tomás}

\begin{tabular}{|c|c|c|c|c|c|c|c|c|c|c|c|c|}
\hline \multirow[b]{2}{*}{ Tiempo } & \multicolumn{4}{|c|}{ Luz plana } & \multicolumn{4}{|c|}{ Luz media } & \multicolumn{4}{|c|}{ Sin luz } \\
\hline & $\begin{array}{c}\text { Planta } \\
1\end{array}$ & $\begin{array}{c}\text { Planta } \\
2\end{array}$ & $\begin{array}{c}\text { Planta } \\
3\end{array}$ & Prom. & $\begin{array}{c}\text { Planta } \\
1\end{array}$ & $\begin{array}{c}\text { Planta } \\
2\end{array}$ & $\begin{array}{c}\text { Planta } \\
3\end{array}$ & Prom. & $\begin{array}{c}\text { Planta } \\
1\end{array}$ & $\begin{array}{c}\text { Planta } \\
2\end{array}$ & $\begin{array}{c}\text { Planta } \\
3\end{array}$ & Prom. \\
\hline Día 15 & & & & & & & & & & & & \\
\hline Día 17 & & & & & & & & & & & & \\
\hline Día 19 & & & & & & & & & & & & \\
\hline Día 21 & & & & & & & & & & & & \\
\hline Día 23 & & & & & & & & & & & & \\
\hline Día 25 & & & & & & & & & & & & \\
\hline Día 27 & & & & & & & & & & & & \\
\hline Día 29 & & & & & & & & & & & & \\
\hline
\end{tabular}

¿Cómo influye la luz el número de flores en plantas de fríjol?

Grafique el número de flores en una hoja de papel milimetrado o en Excel. El eje de las x corresponde al tiempo (día) y en el eje de la y número de flores.

Conclusiones.

Tabla 8. Cuantificación de vainas en plantas de fríjol

\begin{tabular}{|c|c|c|c|c|c|c|c|c|c|c|c|c|}
\hline \multirow[b]{2}{*}{ Tiempo } & \multicolumn{4}{|c|}{ Luz plana } & \multicolumn{4}{|c|}{ Luz media } & \multicolumn{4}{|c|}{ Sin luz } \\
\hline & $\begin{array}{c}\text { Planta } \\
1\end{array}$ & $\begin{array}{c}\text { Planta } \\
2\end{array}$ & $\begin{array}{c}\text { Planta } \\
3\end{array}$ & Prom. & $\begin{array}{c}\text { Planta } \\
1\end{array}$ & $\begin{array}{c}\text { Planta } \\
2\end{array}$ & $\begin{array}{c}\text { Planta } \\
3\end{array}$ & Prom. & $\begin{array}{c}\text { Planta } \\
1\end{array}$ & $\begin{array}{c}\text { Planta } \\
2\end{array}$ & $\begin{array}{c}\text { Planta } \\
3\end{array}$ & Prom. \\
\hline Día 15 & & & & & & & & & & & & \\
\hline Día 17 & & & & & & & & & & & & \\
\hline Día 19 & & & & & & & & & & & & \\
\hline Día 21 & & & & & & & & & & & & \\
\hline Día 23 & & & & & & & & & & & & \\
\hline Día 25 & & & & & & & & & & & & \\
\hline Día 27 & & & & & & & & & & & & \\
\hline Día 29 & & & & & & & & & & & & \\
\hline
\end{tabular}

¿Cómo influye la luz el número de vainas en plantas de fríjol?

Grafique el número de flores en una hoja de papel milimetrado o en Excel. El eje de las x corresponde al tiempo (día) y en el eje de la y número de vainas.

¿Qué operaciones y relaciones sobre los números, se emplean en una experiencia agrícola urbana?

¿Cuáles son los objetos bidimensionales y tridimensionales que identifica en la experiencia agrícola urbana?

¿La forma de los tallos, hojas y raíces, es bidimensional o tridimensional?

¿Qué unidad de medida debió emplear para medir el crecimiento de las plantas?

Al representar en un diagrama de barras los datos recolectados de crecimiento de las plantas ¿cuál es la forma de la gráfica?

¿Cuáles son los elementos del laboratorio virtual: "Experiencia agrícola urbana" que le permiten su aprendizaje en las ciencias y en el arte?

¿Qué actividades permite hacer el aula virtual?

¿Qué aportes identifica en el aula virtual para analizar el crecimiento de las plantas?

¿Cuáles son los beneficios del uso del laboratorio virtual Experiencia agrícola urbana, como mecanismo de análisis en el desarrollo de proyectos de seguridad alimentaria y biotecnología en su comunidad?

¿Cuáles son los beneficios para el ecosistema de cultivar en nuestros hogares?

¿Cuáles son los beneficios en la alimentación de su familia del cultivo urbano controlado?

¿Cuál es la contribución de los cultivos urbanos a la economía del hogar?

¿Cuáles son los cuidados que se deben tener con las plantas durante el desarrollo del experimento?

Conclusiones del ensayo 1 y 2 . 
Implementación de las competencias STEAM (ambientales, tecnológicas y pedagógicas), para cursos de básica primaria en colegios de la ciudad de Bogotá D.C. mediante una experiencia agrícola urbana.

\section{Universidad Santo Tomás}

Semana 6. Festival gastronómico (Componente artístico): Elaboración de platos que involucren el fríjol en Colombia, Latino América y a nivel mundial.

¿Cuáles son los platos que se pueden preparar con los frutos obtenidos en la experiencia agrícola urbana?

¿Cuál es el centro de origen del fríjol?

¿Cuáles son las cualidades nutricionales del fríjol y otras leguminosas?

Dibuja la planta de frijol que consideres más bella de tu experimento.

Preguntas Integradoras:

Desde lo Tecnológico

Desde lo Pedagógico:

¿Cuáles son las contribuciones del desarrollo del proyecto acorde al modelo pedagógico del colegio?

¿Qué competencias en matemáticas, ciencias naturales, ciencias sociales, tecnologías y artes potencia el desarrollo del proyecto?

¿Cuáles son las estrategias digitales que pueden apoyar el proceso de aplicación del proyecto integrador con los estudiantes?

\begin{tabular}{|c|c|c|c|}
\hline TIEMPO & ACTIVIDAD & RESULTADO & PREGUNTAS INTEGRADORAS \\
\hline $\begin{array}{l}4 \quad \text { semanas } \\
\text { (Agosto) }\end{array}$ & $\begin{array}{l}\text { Piloto con el equipo docente } \\
\text { - } \quad \text { Registro de medidas } \\
\text { y registro fotográfico } \\
\text { - Sistematización de } \\
\text { resultados }\end{array}$ & $\begin{array}{l}\text { Desarrollo de la guía } \\
\text { metodológica }\end{array}$ & $\begin{array}{l}\text { ¿Si hablamos de un enfoque STEAM, } \\
\text { cuáles pueden ser los aspectos } \\
\text { pedagógicos a resaltar con los chicos? } \\
\text { ¿Cómo articular como eje transversal } \\
\text { en el trabajo con los chicos, el } \\
\text { concepto de seguridad alimentaria } \\
\text { vista desde la ciencia? } \\
\text { ¿Es posible hablar de ciudadanía } \\
\text { científica para que padres de familia se } \\
\text { involucren y qué rol pueden jugar? }\end{array}$ \\
\hline $\begin{array}{l}8 \text { semanas } \\
\text { (septiembre- } \\
\text { octubre) }\end{array}$ & $\begin{array}{l}\text { Implementación de la guía } \\
\text { - } \quad \text { Registro de medidas } \\
\text { y registro fotográfico } \\
\text { - Sistematización de } \\
\text { resultados }\end{array}$ & $\begin{array}{lr}\text { Fase de cultivo y } \\
\text { cosecha } & \\
\text { Identificación } & \text { de } \\
\text { Competencias STEAM y } \\
\text { de sostenibilidad }\end{array}$ & $\begin{array}{l}\text { ¿Cómo construir una historia de la } \\
\text { planta escogida para el crecimiento } \\
\text { acompañada de imágenes y alguna } \\
\text { información de su naturaleza? } \\
\text { ¿Qué aplicaciones digitales pueden } \\
\text { ayudar a graficar o presentar sentidos } \\
\text { de tiempo de crecimiento, fragilidad o } \\
\text { fortaleza en el color? }\end{array}$ \\
\hline
\end{tabular}


Implementación de las competencias STEAM (ambientales, tecnológicas y pedagógicas), para cursos de básica primaria en colegios de la ciudad de Bogotá D.C. mediante una experiencia agrícola urbana.

\section{Universidad Santo Tomás}

\begin{tabular}{|c|c|c|c|}
\hline $\begin{array}{ll}12 & \text { semanas } \\
\text { (agosto-octubre) }\end{array}$ & $\begin{array}{l}\text { Exploración del simulador } \\
\text { virtual } \\
\text { - Registro de datos en } \\
\text { el formato Excel }\end{array}$ & 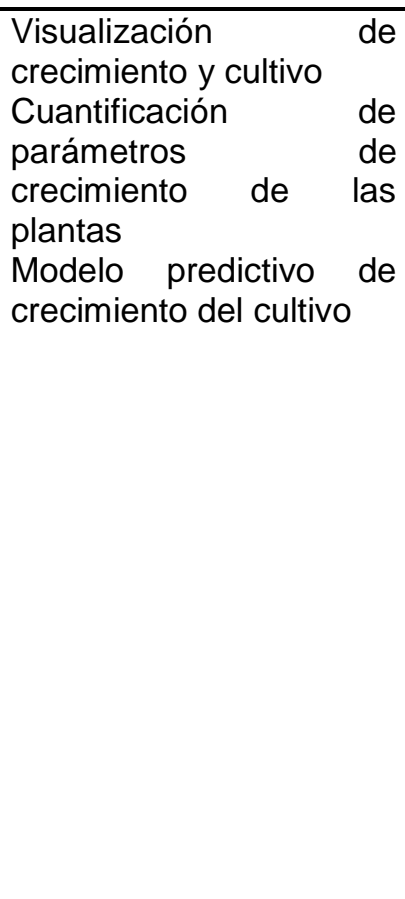 & $\begin{array}{l}\text { ¿Cómo realizar un diario de campo del } \\
\text { proceso? } \\
\text { ¿Cómo realizar un cuento sobre la } \\
\text { planta que permita describirla según la } \\
\text { imagine su dueño, detallar } \\
\text { características y número de ellas? } \\
\text { ¿Cuantos frijoles utiliza una familia } \\
\text { para realizar una cena o un almuerzo, } \\
\text { los ha contado? } \\
\text { ¿cuántas familias y en qué regiones se } \\
\text { come esta planta? } \\
\text { ¿Cuántos nutrientes puede aportar esa } \\
\text { planta al cuerpo humano? } \\
\text { ¿Cuantos días o semanas necesita, la } \\
\text { planta para tener frutos? } \\
\text { ¿Cuántos nutrientes necesita la planta } \\
\text { para crecer? } \\
\text { ¿Cuantos elementos necesita la planta } \\
\text { para poder crecer? } \\
\text { ¿Cuáles y en qué medida los } \\
\text { cambiaría si pensara que podría ser } \\
\text { mejor? }\end{array}$ \\
\hline $\begin{array}{l}\text { 1 semana (última } \\
\text { semana de } \\
\text { octubre) }\end{array}$ & $\begin{array}{l}\text { Festival gastronómico } \\
\text { - Grabación de la } \\
\begin{array}{l}\text { preparación } \\
\text { alimentos }\end{array}\end{array}$ & $\begin{array}{lr}\text { Informe de } & \text { los } \\
\text { contenidos nutricionales } \\
\text { identificados en la } \\
\text { comida preparada }\end{array}$ & $\begin{array}{l}\text { ¿Qué papel juegan los nutrientes en la } \\
\text { salud? } \\
\text { ¿Cuáles son las enfermedades que se } \\
\text { pueden originar por una mala } \\
\text { nutrición? } \\
\text { ¿Cuántos tipos de comidas podría } \\
\text { elaborar su familia con el alimento } \\
\text { producto de esa planta? } \\
\text { ¿Cuánto tiempo cree que se demora la } \\
\text { preparación de este alimento? } \\
\text { ¿Qué sensación le da comer un } \\
\text { alimento que usted mismo ha o podría } \\
\text { cultivar? } \\
\text { ¿A quiénes le gustaría mostrar un plato } \\
\text { realizado con el tipo de comida } \\
\text { producto de la planta que cultivó? }\end{array}$ \\
\hline
\end{tabular}

\section{Referencias:}

Aguirre, J. P. S., Vaca, V. D. C. C., \& Vaca, M. C. (2019). Educación STEAM: entrada a la sociedad del conocimiento. Ciencia Digital, 3(3.4.), 212-227.

García Murillo, P. G., Martín Perico, J. Y., Parada Romero, L. B., \& Garibello Suan, B. (2020). Diseño metodológico para la implementación de competencias STEAM en un proyecto de agricultura urbana, ajustado a condiciones de COVID-19 y con estudiantes de $5^{\circ}$ grado en Bogotá, Colombia. En E. Serna M, Revolución en la formación y la capacitación para el siglo XXI Vol. II (pág. 674). Medellín: Editorial Instituto Antioqueño de Investigación.

García Murillo, P. G. (2019). Compatibilidad de un aislamiento del género Trichoderma con ocho fungicidas utilizados en el cultivo de rosa. Redes de Ingeniería, 10(1), 5-12. https://doi.org/10.14483/2248762X.15091 
García Murillo, P. G. (2018a). Evaluación de tres desinfectantes contra el moho gris causado por Botrytis cinerea en el cultivo de rosa. Redes de Ingeniería, 9(1), 39-45. https://doi.org/10.14483/2248762X.13882

García Murillo, P. G. (2018b). Producción de orellanas (Pleurotus ostreatus) como alternativa para el tratamiento de residuos sólidos de origen vegetal en Bogotá D.C. Redes de Ingeniería, 9(1), 26-31. https://doi.org/10.14483/2248762x.13858

García Murillo, P. G. (2015). Bioprospección de microorganismos nativos como alternativa de manejo de enfermedades en cultivos de la Sabana de Bogotá. Revista CITAS, 1(1), 9-19. Retrieved from http://portal.ustadistancia.edu.co/citas/ediciones/vol-1/files/assets/basic-html/page9.html

García Murillo, P. G. (2014). Evaluación de tres aislamientos del género Trichoderma, en combinación con pregerminación controlada de semillas, contra Botrytis cinerea y Rhizoctia solani. Actualidades Biológicas, 36, 236-237. Retrieved from http://matematicas.udea.edu.co/ actubiol/actualidadesbiologicas/resumenesviiiCongMicologia. pdf

García-Peñalvo, F. J. (2016). Proyecto TACCLE3-Coding. XVIII Simposio Internacional de Informática Educativa SIIE.

Furman, M. (2016). Educar mentes curiosas: la formación del pensamiento científico y tecnológico en la infancia: documento básico, XI Foro Latinoamericano de Educación.

Nugent, N., \& Rhinard, M. (2015). The european commission. Macmillan International Higher Education.

Perales Palacios, F. J., \& Aguilera Morales, D. (2019). Educación STEAM: algo más que unas siglas.

Rodríguez-Cepeda, R. (2016). Aprendizaje de conceptos químicos: una visión desde los trabajos prácticos y los estilos de aprendizaje. Revista de investigación, desarrollo e innovación, $7(1)$, 63-76.

Trujillo, F. (2015). Aprendizaje basado en proyectos. Infantil, Primaria y Secundaria. Ministerio de Educación. 